\title{
HOMELAND SECURITY AND EMERGENCY MANAGEMENT IN INSTITUTIONS OF HIGHER EDUCATION (IHE): TEXAS CASE STUDY
}

\author{
MAGDALENA ANNA DENHAM \& ASHISH KUMAR KHEMKA \\ Department of Security Studies, Sam Houston State University, U.S.A.
}

\begin{abstract}
This exploratory case study adopted the classical content analysis (CCA), cross case mixed strategy and Qualitative Data Miner (QDA) correspondence analysis of websites across 41 accredited public Institutions of Higher Education (IHE) in the state of Texas. The conceptual framework guiding the study was based on adaptive resiliency and Disaster Resilient University (DRU) paradigms. The goal of this inquiry was to determine (a) the most common organizational arrangements adopted across the IHEs in Texas to integrate emergency management functions on their campuses?; (b) the scope of most common activities and engagement performed by IHEs in Texas with respect to supporting the DRU mission across the cycle of emergency management?; (c) competencies and job definitions of officials specifically involved in supporting the all-hazards approach to emergency management on IHE campuses in Texas?; (d) training, exercise and certification standards as well as emergency notification systems commonly adopted among the IHEs in Texas; and (e) the type of educational, awareness, and outreach programs which can be identified across Texas IHEs in support of the DRU mission? Common and divergent themes, as well as implications for IHE leadership practice will be discussed.

Keywords: emergency management, homeland security, higher education, disaster resiliency, incident management cycle, campus safety and security, preparedness, response, recovery, mitigation.
\end{abstract}

\section{INTRODUCTION}

'Emergency management was an afterthought at many IHEs prior to 2001, and if it was a recognized need, it was an ancillary responsibility of a police officer, administrator, or health and safety professional. There simply was no officially designated position that dealt with campus emergencies, and the level of support for such position was extremely low' [1]. American Institutions of Higher Education (IHEs) face a variety of potential threats and hazards, be it human-caused [2-6], technological, or natural within their campus settings [3]. From the Homeland Security and Emergency Management (HSEM) perspective, IHEs have been defined as critical pieces of American infrastructure under the Education Facilities Subsector of the Government Facilities Sector [7, 8]. Brenner [9] explained the national importance of IHEs, underscoring their role in producing cultural, intellectual, and social resources, housing physical buildings on campuses, material resources used or housed in campus facilities, human resources, intellectual resources such as research, and infrastructure like important utilities.

Aligning with one of the core missions of national Homeland Security strategy [10] strengthening national preparedness and resilience - a multi-threat and all-hazard approach has been proposed when creating plans along the emergency management cycle comprised of preparedness, response, recovery and mitigation [12]. Inclusion of sound practices in HSEM along the emergency management cycle among IHEs would contribute to what Kapucu and Khosa [13] defined as a Disaster Resilient University (DRU); a DRU represents an institution capable of adapting to the aftermath of a disaster and learning through its experience to become better prepared for such instances in the future [13, 14]. 
Inarguably, events such as the 2007 Virginia Tech shooting have become a growing concern for campus officials [15]. Concurrently, natural disasters such as 2005 Hurricane Katrina have highlighted the complexity of navigating relationships with emergency response organizations such as FEMA, the National Guard, the American Red Cross (ARC) and other relief personnel by the IHEs. For example, during Hurricane Katrina the Louisiana State University (LSU) assembly center was transformed into an acute care facility, triaging 15,000 evacuees and treating 6,000 patients while the institution worked to effectively communicate essential messages to the public through previously set-up methods and avenues of communication [16]. In 2003, then FBI Director Robert S. Mueller III in a report to Senate Select Committee on Intelligence of the United States Senate identified IHEs' vulnerabilities to a variety of threats and difficulties related to maintaining the balance between allowing for the free exchange of ideas and safeguarding the integrity of the campus and its students [9]. Meanwhile, modifications to the Jean Clery Disclosure of Campus Security Policy and Campus Crime Statistics Act of 1990 (20 U.S.C. $\$ 1092$ (f) [hereafter referred to as 'the Act']) have expanded responsibilities of campus officials to: distribute immediate emergency notification warnings to the campus community upon confirmation of a dangerous situation on campus involving an immediate threat to the health or safety of students or staff regardless of whether a crime is involved. Examples of emergencies that would warrant such a notification include: an active shooter on campus, a riot, a bomb threat, a tornado, a fire and similar situations involving active and palpable threats. Every institution must conduct yearly tests of emergency response and follow-through activities designed for assessment and evaluation of emergency plans and capabilities [17]. Moreover, in states such as Texas noting the increasing phenomenon of legislative support for the right-to-carry on campus [18], IHEs' administrative leaders have been challenged with defining policies, implementation procedures, and evaluation criteria to ensure compliance with new state laws while providing for safety and security of the entire campus community. Admittedly, the increasing role of HSEM functions among IHEs requires increased commitment to dedicate resources, personnel, and organizational structures in their support. Of increasing importance is thus defining what are the best organizational arrangements, collaborative practices, or supportive mechanisms available to IHEs in their all-hazards mission towards achieving the DRU mission. Some arguments have been raised that IHEs are not as properly secure as they should be highlighting campus officials tasked with such planning and securing lack the training and experience necessary to prevent, plan for, or respond to incidents $[19,20]$. Furthermore, collaboration challenges between IHEs' administration and law enforcement have been reported [20, 21]. Kerr [22] who examined public, private not-for-profit and proprietary IHEs in the Midwest for Clery Act compliance reported 'a majority of the institutions did not comply with the requirements of the law'.

Furthermore, Nicoll and Owens [23] noted emergency planning often meets with conflict or resistance as some departments or administrators within the IHE may not want to spend limited resources, such as time and money, on developing response measures that may never be used. Support from those in leadership positions fosters implementation and funding for preparedness and resiliency-building measures [24]. In turn, evidence of administrative support may be reflected in the level of institutionalization of HSEM functions at the IHE. Nonetheless, beyond standardized resources disseminated to guide IHEs through planning and preparedness activities [25, 26], there is lacuna of systematic research conducted among the IHE's regarding common structures and arrangements adopted by IHEs themselves to institutionalize the emergency management functions to fit into the overall concept of IHEs' operations. To administrative leadership in IHE this may be especially troubling given legal, psychological, and societal impacts that characterize high consequence events. Moreover, in spite of increasing legislative mandates 
both at federal and state levels such as the Clery Act, National Incident Management System (NIMS) [27], or campus carry provisions, absence of frameworks for integration of HSEM functions by administrative leaders may severely impede the capability of those institutions to implement those mandates successfully.

To that end, our exploratory case study aims to examine, using IHEs' data from the state of Texas, the degree and scope of the integration of the HSEM functions (if evident) into IHEs' operations. Specifically, the goal of our study is to elicit answers to the following questions: (a) What if any are the most common organizational arrangements adopted across the IHEs in Texas to integrate emergency management functions on their campuses?; (b) What is the scope of most common activities and engagement performed by IHEs in Texas with respect to supporting the DRU mission across the cycle of emergency management?; (c) What are the competencies and job definitions of officials specifically involved in supporting the all-hazards approach to emergency management on IHE campuses in Texas?; (d) What are the training, exercise, and certification standards as well as emergency notification systems commonly adopted among the IHEs in Texas; and (e) What type of educational, awareness, and outreach programs can be identified across Texas IHEs in support of the DRU mission?

\section{CONCEPTUAL FRAMEWORK}

Integration of HSEM functions within IHEs will be assessed though the adaptive resilience model [28] represented by Figure 1. Specifically, institutional adaptive capacities related to mitigation and preparedness in support of response and recovery and reflected in organizational arrangements, leveraging of community capital, utilization of social capital, and application of communicative and collaborative processes will be sought. Because of 'diversified and decentralized structure' [29] of the IHE campuses into numerous colleges or schools, with each containing various colleges or departments, challenges could arise stemming from the differences of how each operates, communicates, and is organized. Therefore, assessing organizational arrangements adapted for emergency management across a range of IHEs may illuminate specific solutions to best address unique challenges inherent in such decentralization. A DRU is an IHE that has built 'adaptive capacities through social capital development, community competence, and strong communications and information systems' [13]. By emphasizing resilience, IHEs are focusing more on what they can do for themselves and how they can strengthen their own capabilities [30]. Incidentally, exploring whether emergency management practices across the cycle of emergency management have become institutionalized within the IHEs themselves, is an important step in gauging reliance on internal capabilities.

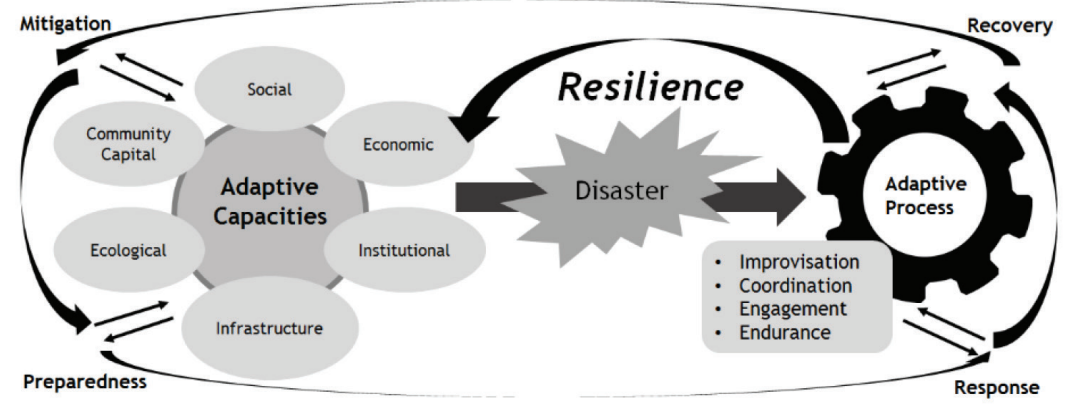

Figure 1: Conceptual model of local disaster resilience. (Source: Ross, 2013. Copyright) 
In addition, universities become resilient by openness and transparency with their students, staff, faulty, and visitors about emergency management plans [13]. One example of this is how universities are publicizing disaster preparedness and emergency management information on their campus websites, making it possible for more people to become knowledgeable about response and resilience steps of the IHE [9]. Another aspect of resilience relates to training and certification of certain faculty and staff on campuses [13]. Griffin [29] suggested reaching beyond students and integrating faculty and staff should be included in the safety and security education on campuses. Through this education, faculty and staff will be better prepared to assist the IHE in its safety and security efforts, resulting in more people on campus equipped with the knowledge to assist in the preparation for and response to a threat or hazard, as well as more people to spread the knowledge to even more people on campus [29]. By training students, faculty, and staff through such means as presentations and corresponding documents, IHEs become better capable to prepare for and respond to a threat or hazard through the help of the individuals on their campuses. Awareness of what roles they will need to fulfil to ensure the continuity of university operations after a disaster has occurred increases the preparedness and resilience of the IHEs and allows for fostering of partnerships with larger communities [31]. When IHEs cooperate, coordinate and communicate externally, they develop social bonds with groups who will assist them in crisis. Familiarity with the first responders, government entities, and non-profit organizations further enhances preparedness and resilience emergencies [23]. Among the partnerships, coordination with first responders and emergency personnel [29] especially helps to encourage communication, assistance and the sharing of information between the groups involved.

\section{METHODOLOGY}

Because the goal of our research is exploratory, a qualitative research paradigm will be applied [32]. Specifically, due to the pragmatic lens of the researchers, the case study design has been selected as optimal. The unit of analysis (i.e. IHE) reflects criteria suggested by Yin [33] because it represents an organization. Organizations are bounded both geographically and administratively and as such lend themselves to case study design inquiries. The embedded unit of analysis [33] is represented by IHEs' websites.

\subsection{Sampling Scheme and Data Source}

Texas has endured numerous disasters and catastrophic incidents over the past century, dating back to the hurricane that made downfall in Galveston in 1900, which claimed over 6,000 lives [34] to more recent events such as Hurricane Rita in 2005 and Hurricane Ike in 2008 which claimed 120 and 135 lives respectively, and resulted in mass scale evacuations [35]. In a study on the impact of Hurricane Rita on a IHE in Texas, Lamar University, the findings indicated that the university suffered approximately $\$ 38$ million in damage, including $\$ 4.4$ million in lost revenue due to physical damage and insufficient response and recovery planning prompted by issues such as communications failures, information technology failures and the inability to resume classes in a timely manner [36]. Texas is prone to diverse natural hazards, of which the most frequent are a) inline river flooding; b) hurricane and tropical storms and c) tornadoes. Texas has had more federally declared disasters than any other state [34], in fact, in several instances, it has received multiple disaster declarations in a single year. In 2016, it received FEMA disaster declaration for severe storms and flooding in March, April and June [37]. 
In addition, the state has also been subject to numerous technological and manmade disasters, several of them impacting IHEs directly. One of the watershed manmade events at an IHE in Texas was the 1966 mass shooting at the University of Texas at Austin (UTA) campus, in which a single individual killed 14 victims. The ineffective response by the police prompted the formation of Special Weapons and Tactics (SWAT) teams around the country [38]. Another notable incident caused by a combination of human error and technology was the 1999 bonfire collapse at Texas A\&M University, which killed 11 individuals and sent 28 to hospitals [39]. While these have been some of the focusing IHE disasters in Texas, there continue to be persistent incidents of similar, yet less severe magnitude periodically, such as an explosion in 2010 at a Chemistry laboratory at Texas Tech, the investigation of which highlighted systemic deficiencies in university safety management practices [40].

The IHE's selected for this study were obtained from a dataset of 545 accredited IHEs in Texas which is provided by the US Department of Education (US DOE, 2016). The selection process is outlined in Figure 2. Of the 545 IHEs, a further criterion of the IHE being accredited by the 'Southern Association of Colleges and Schools Commission on Colleges' (SACSCOC) was applied, 170 IHE's fulfilled this criterion. This dataset was further filtered, using the criteria of whether the IHE belonged to one of the 7 state systems in Texas, resulting in a dataset of 41 IHEs. The entire dataset selection was limited to publicly controlled universities because they are subject to various federal and state laws, such as the Homeland Security Presidential Policy Directive 5 (HSPD-5) [27], which established the National Incident Management System (NIMS), and Executive Order 40 by Governor Perry in Texas, which establishes NIMS as the incident management framework for the state [27]. An example of its adoption by IHEs which meet the criteria is IHE's in the University of Texas System, which are guided by policy stating that their emergency management program will incorporate NIMS and the Incident Command System (ICS) as part of their emergency preparedness program [41].

SACSCOC was selected as the accreditor because since its foundation in 1895, it has established itself as the primary regional accreditor for 11 southern states in the nation, including Texas. A regional accreditor, in comparison to a national accreditor, conducts a comprehensive assessment of IHEs in a designated geographic area [42]. The assessment includes all instructional sites, including online, and comprises of multiple standards. Of

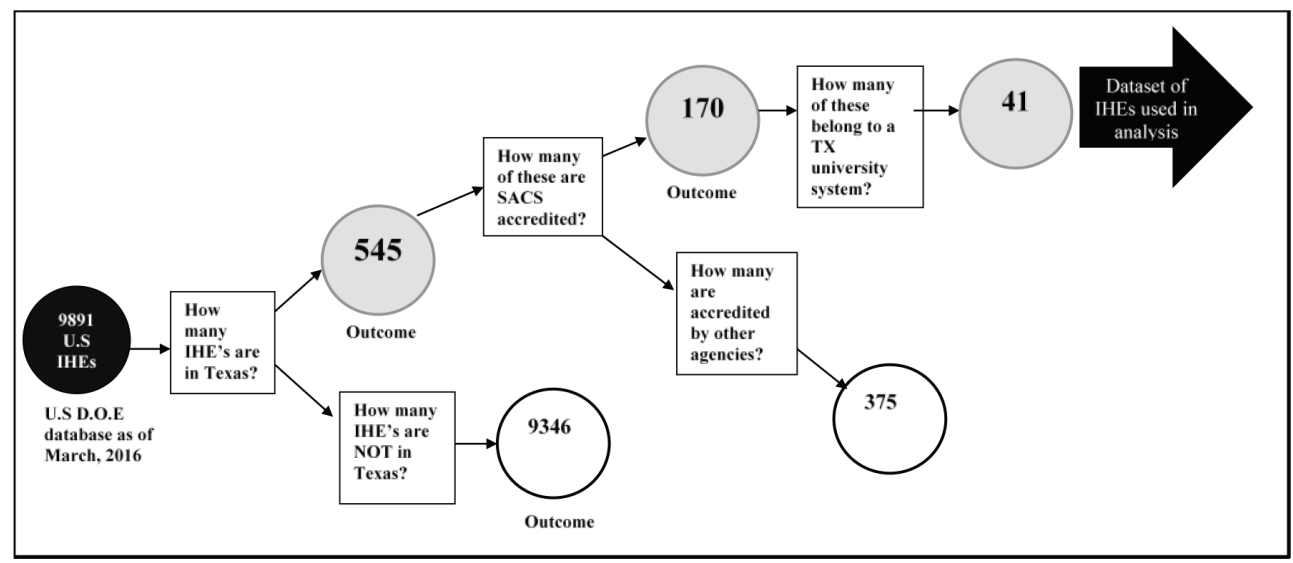

Figure 2: IHE case selection process. 
significant relevance to study are SACSCOC standards 3.11.1, which requires the institute to maintain 'control over its physical resources' [43] and standard 3.11.2, which requires the institution to take steps to provide a 'healthy, safe and secure environment for all members of the campus community' [42]. In addition to applying rigorous standards, regional accrediting bodies such as SACSCOC maintain comparative standards across each other and serve as the gatekeepers for Title IV funds, which is a major source of federal aid [44]. In comparison, national accreditors typically cater to private IHEs or those whose missions focus either on career education or religious education [42].

\section{DATA ANALYSIS}

In order to conduct text and image analysis of IHE websites to search for content related to HSEM functions comprised therein, classical content analysis (CCA), [45, 46] was adopted. CCA 'allows the analyst systematically to examine small or large amounts of textual information and systematically identify the most salient features contained in its communication content by determining, comparing, and contrasting the frequencies of each feature' [47]. Furthermore, considering the [48] call for using multiple qualitative data analysis techniques whenever appropriate and possible, CCA was supplemented with a strategy developed by Miles et al. [49] to organize, arrange, and visually represent the data. Miles et al. [49] expressed that cross-case mixed strategy involved discerning a set list of elements from literature, applying the elements to chosen cases (i.e. IHEs), evaluate the cases using for each a matrix created from said elements, and then identifying the salient elements by comparing across the matrices.

Finally, after the themes had been extracted via CCA, and cross-case mixed strategy, they were further subjected to correspondence analysis, a graphical technique that allows researchers to conduct a mapping cross-case analysis of emergent themes. Specifically, a correspondence analysis is an exploratory multivariate technique that involves factoring categorical (i.e. nominal level) variables and graphing them (i.e. mapping them) in a property space that displays their associations in multiple (i.e. two or more) dimensions [50]. The QDA Miner 5.0 software program [51] was used to conduct the correspondence analysis. This analysis represented what [52] referred to as a crossover mixed analysis, whereby the analysis types associated with one tradition (i.e. quantitative analysis: correspondence analysis) were used to analyse data associated with a different tradition (i.e. qualitative data: emergent themes). Specifically, we utilized a qualitative-dominant crossover mixed analysis wherein the qualitative analysis was dominant, while, simultaneously, we deemed the addition of quantitative analysis as being helpful in providing richer data and interpretations [52].

\section{RESULTS AND DISCUSSION}

Overall, the CCA of 41 IHEs' websites yielded 10 supra-codes (i.e. organization, job role and title, competencies, scope of activities, crisis typology, frameworks and DRU features, exercises, emergency notifications, education and outreach). The codebook contained 85 sub-codes that contributed to subsequent cross-case correspondence analysis. Website data were organized in each case by document variables (e.g. organizational charts, safety manuals, organizational notes, checklists). Organizationally, as illustrated by frequency of code distribution in Figure 3, the HSEM function may be nested at the University Police Department (or Office of Public Safety), Environmental Health and Safety, may be shared by various divisions or departments, or may reside under a separate Office of Emergency Management (OEM). The latter organization was evidenced in $25.6 \%$ of cases. Our findings partially 


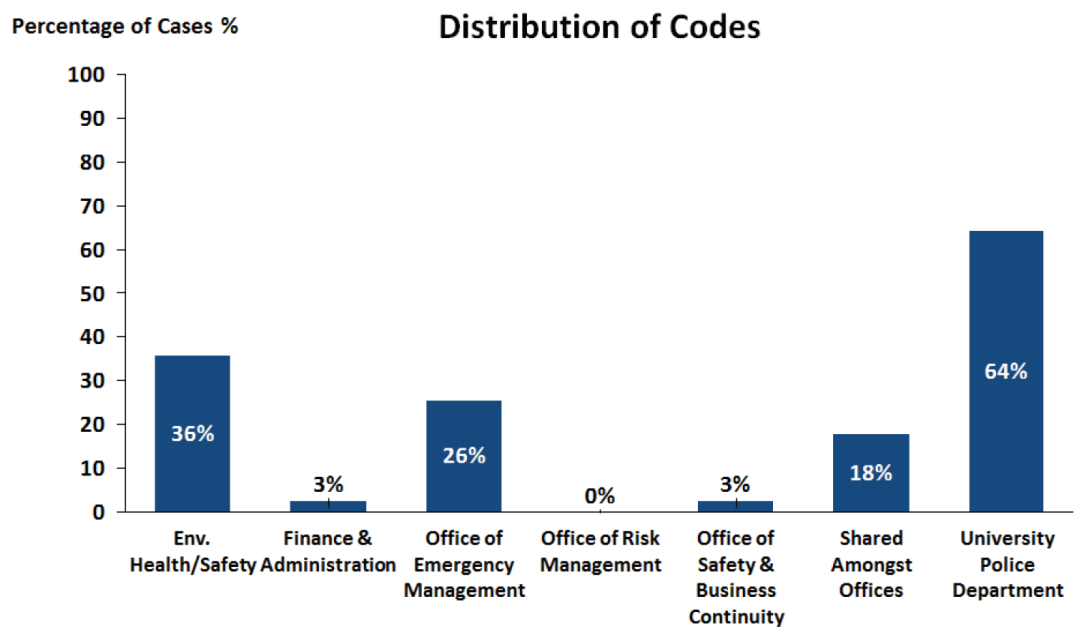

Figure 3: Emergency management function placement. (Source: Author data using QDA Miner 5.0)

confirm previous reports [1] that emergency management departments at IHEs in the United States are a division of police or public safety (37.9\%) and $24.1 \%$ are stand-alone departments. Emerging themes in this study further suggest four general models for integrating HSEM have been adopted by IHEs in our sample: (a) collateral function of unit/division with the most relevant safety and security expertise and engagement on campus; (b) collateral shared function of units/ divisions with the most relevant safety and security expertise and engagement on campus; (c) collateral function of collegiate administrative and academic teams (i.e. executive groups, incident management teams and behavioural response teams) with support of units/divisions with the most relevant safety and security expertise and engagement on campus; and (d) dedicated unit/division established for the purpose to oversee and coordinate HSEM at the University.

Analysis of codes related to job role and title illuminated that HSEM functions have been assumed at various levels of organizations by officers (e.g. Safety Officer, Public Affairs Officer), mid-level managers (e.g. Emergency Manager), teams, and mid to executive level Emergency Management Coordinators (EMCs) and Directors. Specifically, administrative and academic collegiate teams in charge of HSEM were evidenced in $36 \%$ of cases and EMC/Director roles in $25.6 \%$ of cases. Notably, the only discernible competencies were extracted in relation to the EMC/Director roles theme whereby those positions were characterized by a combination of HSEM academic preparation or HSEM experience preparation or mixture of both. For example, individuals in selected EMC/Director positions possessed degrees in Emergency Management and Disaster Planning, Earth Sciences, Geology, Applied Geography, Public Administration, Political Science or experience in local, state, or federal service through continuity planning, exercise evaluation, incident command experience.

The identification of the most common themes depicting activities related to HSEM (excluding crime/violence and fire prevention functions) is portrayed by Figure 4. Visibly, individuals, teams, and organizational units engaged in HSEM at selected IHEs focused the most on Emergency Response Planning (49\%), Preparedness (46\%), Evacuations (41\%), Mitigation Planning (41\%), Recovery Planning (38\%), integrating Policies and Laws that 


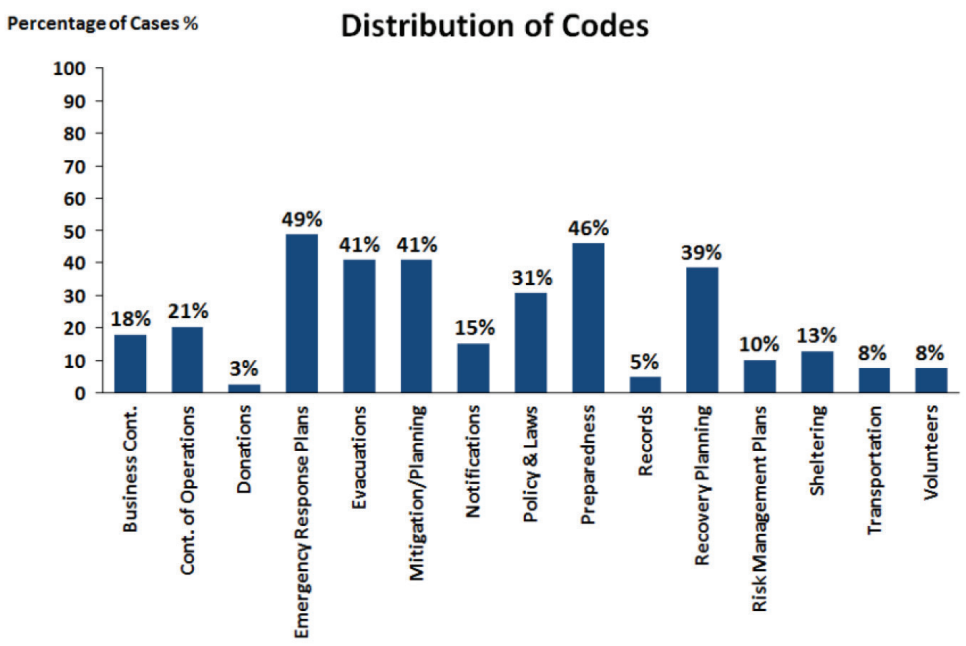

Figure 4: Scope of EM activities evidenced across IHEs in Texas. (Source: Author data using QDA Miner 5.0)

regulate HSEM (33\%). The typology of HSEM activities underscores IHEs' trend towards conceptualization of HSEM along the crisis management cycle (e.g. preparedness, mitigation, response, and recovery). It is noteworthy that Continuity of Operation Planning (COOP) cited by researchers $[53,54]$ as critical to achieving resiliency was reported across websites of more than one-fifth of the IHEs in our sample. Themes extracted from taxonomic analysis of crises occurring at IHEs in Texas, shown in Figure 5, underscore strong focus on active shooter $(60 \%)$ events.

Nearly one fifth of cases addressed crises related to terrorism events on their websites. Importantly, the adoption of all-hazards approach to HSEM was manifested by $25 \%$ of IHEs. Similarly, among the frameworks for best practices in national incident management

\section{Distribution of Codes}

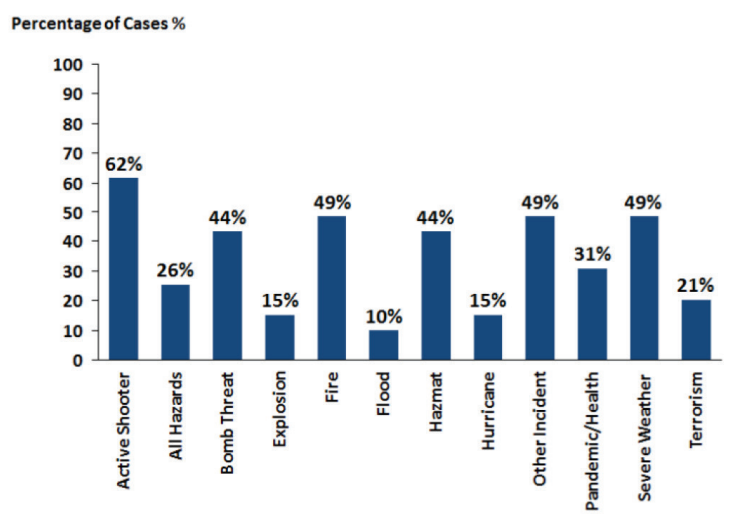

Figure 5: Typology of crises identified across select IHEs in Texas. (Source: Author data using QDA Miner 5.0) 
(e.g. adoption of the NIMS, Incident Command System [ICS], National Response Framework [NRF], National Disaster Recovery Framework [NDRF], Homeland Security Exercise and Evaluation Planning [HSEEP]) as well as training and certifications, IHEs' specific vulnerability and risk assessments, or state guidelines, Figure 6 represents endorsement distribution that reflects moderate and varying levels of integration for each component. Among the exercises, categorized by the sub-codes into discussion-based (games, seminars, table top and workshops) and operations-based (drills, full-scale and functional), IHEs were reporting the largest involvement in table-tops (28.2\%), drills (28.2\%), functional exercises $(10.3 \%)$, workshops $(7.7 \%)$, seminars $(5.1 \%)$ or full-scale multi-jurisdictional $(5.1 \%)$. Relatively low percentage of Universities reported using games such as simulations (2.6\%). Website records signalling adoption of emergency notifications systems confirmed that $71.8 \%$ of all IHEs in this inquiry possess mass communication methods to deliver crisis messaging, advisories and warnings to its populations. Generally, systems such as Mavalert adopted by the University of Texas Arlington, KatSafe adopted by Sam Houston State University, Miner Alert adopted by University of Texas El Paso, or Code Maroon adopted by the Texas A\&M among others represent multi-tiered emergency communication systems to keep campus community informed about emergency situations and rapidly changing conditions from hazardous weather to campus closures, to building emergencies and life-threatening criminal activities. Students, faculty, staff (and in some cases parents) register to receive text messages, voice communications or alerts online on network computers and through wide-range of registered electronic devices. Moreover, emergency communication systems evaluated in this study were amplified by reported web notification applications using social media (33.3\%), sirens $(15.4 \%)$, specially dedicated websites $(28.2 \%)$, or hotlines $(7.7 \%)$ and $25.6 \%$ of the IHEs indicated capability to reach out external communities, agencies and jurisdictions.

Whereas CCA allowed for theme extraction and selected frequency analyses, the results of subsequent cross-case correspondence analyses in QDA Miner 5.0 [51] facilitated forcebased multidimensional scaling to explore deeper connections among codes. Specifically,

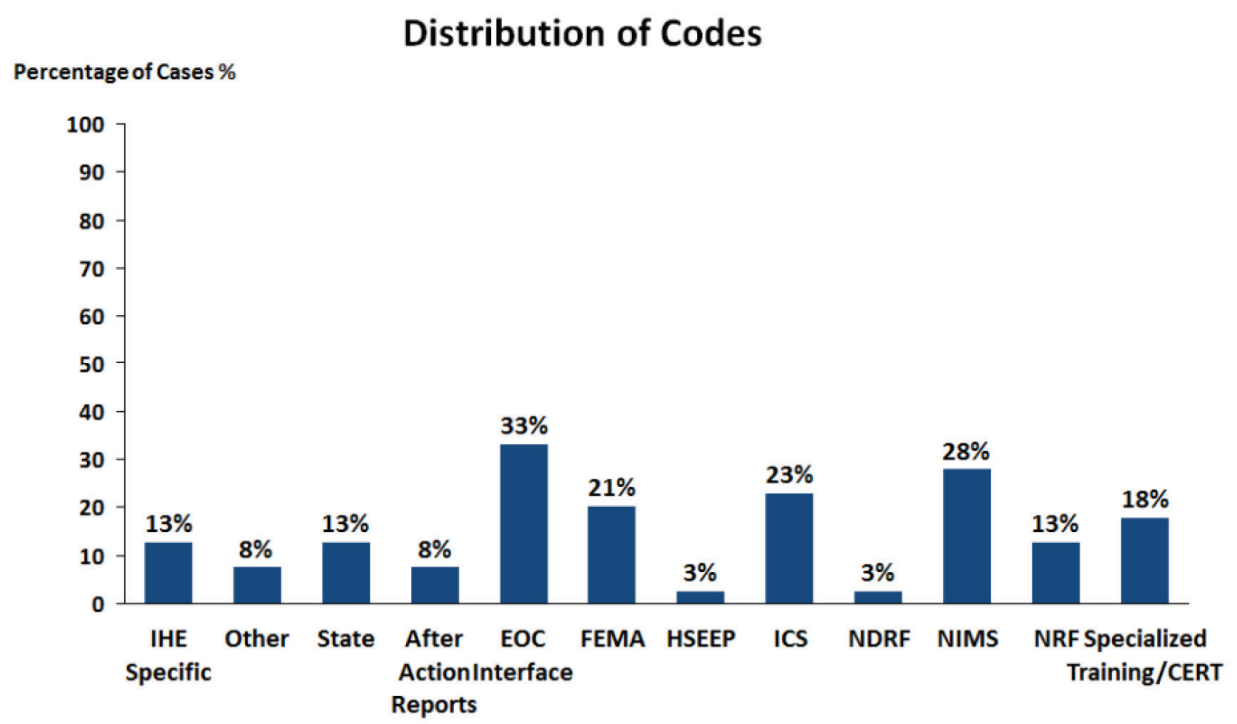

Figure 6: Disaster Resilient University features. (Source: Author data using QDA Miner 5.0) 


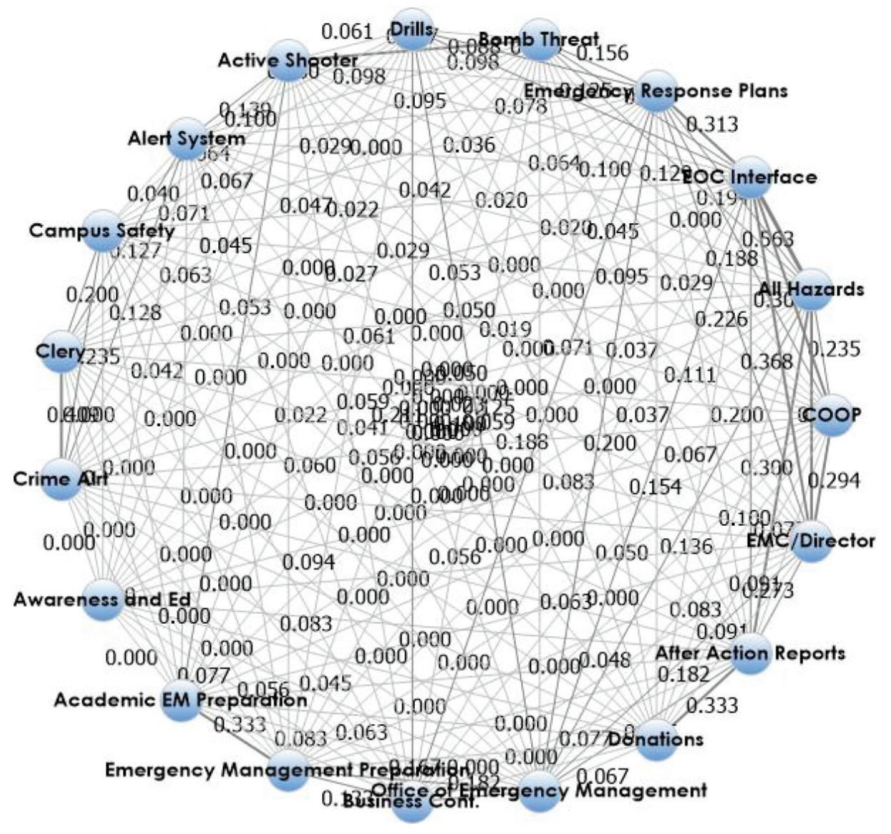

Figure 7: Link analysis. (Source: Author data using QDA Miner 5.0)

visualization of link analysis represented by Figure 7 points to clustering nodes and connections around the position of Emergency Management Coordinator/Director.

Specifically, the presence of a EMC/Director position is associated with Continuity of Operation Planning (COOP), adoption of all-hazards approach to HSEM, compilation of After Action Reports (AARs) and interactions with the Emergency Operations Center (EOC) interface. Similarly, the presence of OEM in organizational structures can be associated with emergency management practical and academic expertise, focus on business continuity, emergency response planning and utilization of drills. Meanwhile, the Clery Act node evidences connections to emergency notification systems and crime alerts as well as campus safety. It may be argued that relatively well developed emergency notification systems among IHEs evidenced in our study result from laws and policies related to national Cleary Act reporting requirements. Concurrently, the multidimensional scaling represented by Figure 8 allows discernment of several clusters of codes. Of most pertinence to our discussion and interpretation is the co-occurrence of items associated with DRUs around the function of the EMC/Director whereby planning across all stages of emergency management cycle (response, mitigation, preparedness and recovery) tends to concentrate. It is also around that node that HSEM frameworks and concepts appear to converge. In contrast, presence of administrative and academic collegiate teams that fulfil the role of HSEM on selected campuses show focus on institution-specific risk assessments as well as links to external agencies such as local EOC or local law enforcement entity for HSEM functions even though their link to the EMC/ Director cluster can be noted as well. Not as strongly linked, clusters around HSEM function residing within Environmental Health and Safety as well as University Police Department (or Public Safety) structures point to generally hazard-specific approach to managing crises based on type; predominant threat represents active shooter events. Inarguably, amidst a variety 


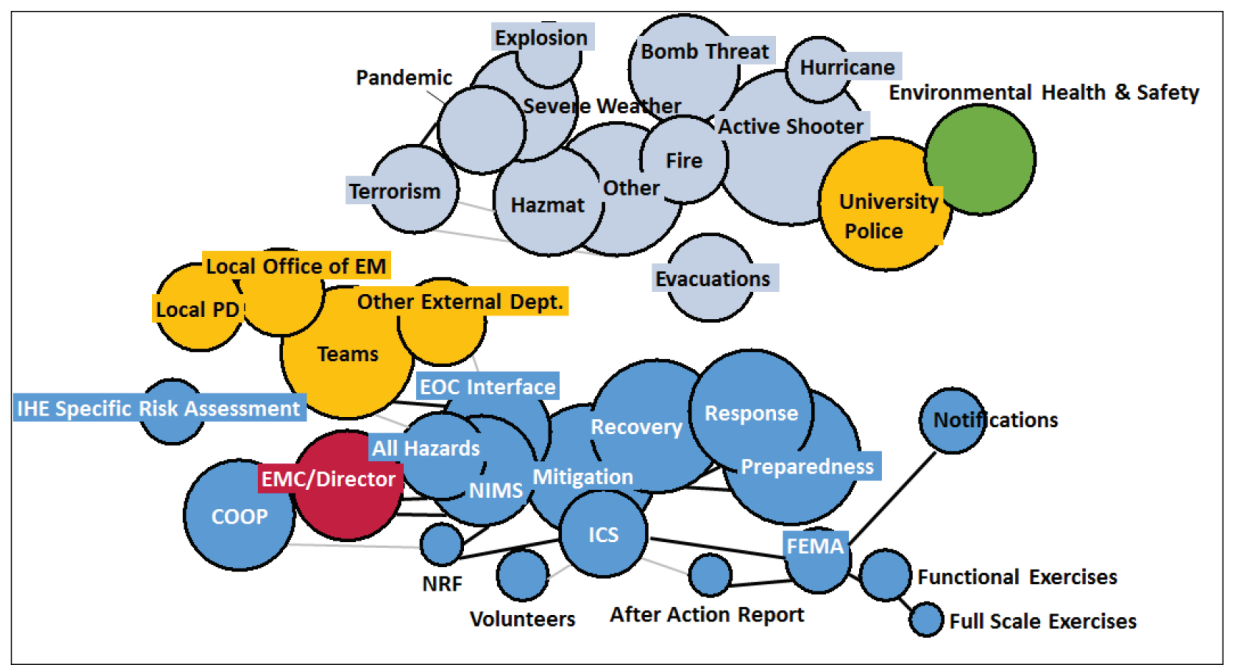

Figure 8: Multidimensional scaling for HSEM integration representing 3 most concentrated theme co-occurrence clusters among 17 yielded by the results. (Source: Author data adapted from output using QDA Miner 5.0)

of HSEM activities, and organizational arrangements that focus on them, only the designated position of EMC/Director at an IHE represents the high level of integration. Those findings can be meaningful and impactful in several ways. First, 'When emergency management is a component of university police, public safety, or environmental health and safety, the department competes for scarce resources not only among university departments but also potentially within its own department. What's more, when the mission, vision and effort of emergency management is intertwined with the programs and organizational dynamics of an overarching or parent department, the result is an obfuscation of emergency management objectives and strategies, which can diminish the quality and effectiveness of emergency management programs' [1]. Therefore, consolidation of various HSEM activities under the designated EMC/Director position and/or within the campus OEM may delineate a shift towards a new administrative and organization entity evolving in educational administration. Consequently, HSEM discipline-focused practical and academic expertise characterizing individuals assigned to EMC/ Director roles may suggest further future need for HSEM professionalization across IHEs. The new profession as it evolves will require ongoing research on future competencies of HSEM practitioners on campus. Clearly, documented presence of the fourth model of organizational arrangement for HSEM (i.e. OEM and dedicated EMC/Director roles) on campuses reaching 25\% representation merits attention. Based on Ross, [28] resiliency model of capability building and adaptation, the OEM model is the only one in our study that mirrors comprehensive emergency management cycle processes.

Markedly, activities of individuals and units/department tasked with emergency management cut across a wide range of hazards and threats, all of which regulated by diverse policies and laws. Indeed, professionals who focus on supporting the DRU mission (DRU, 2015) have called for a crosswalk of policies in various safety and security domains (e.g. Clery Act; DOE Action Guide 2009; National Fire Protection Agency [NFPA] 1600; FEMA Community Preparedness Guide 101; Occupational Safety and Health Act [OSHA] 1910, among others). 
Such efforts may further consolidate requisite knowledge, abilities, skills and competencies of those entrusted with managing crises on college campuses. Clearly, the goal of our study was not prescriptive and our findings and interpretations do not suggest that traditional policing, crime, fire prevention, or occupational health and safety concerns would be relegated to new organizational units and departments across IHEs. However, it is plausible that distinct organizational HSEM structures may secure permanent presence in the ever more complicated environment of campus safety and security.

\section{ACKNOWLEDGEMENTS}

The authors would like to thank Provalis team for assistance with utilization and interpretation of QDA Miner 5.0 functionality and Dr. Ashley Ross for permission to use the resiliency model in our study.

\section{REFERENCES}

[1] Farris, D. \& McCreight, R., The professionalization of emergency management in Institutions of Higher Education. Journal of Homeland Security and Emergency Management, 11(1), pp. 73-94, 2014. https://doi.org/10.1515/jhsem-2013-0074.

[2] Hellwig-Olson, B., Jacobsen, M., \& Mian, A., Contemporary issues in campus crisis management. Campus crisis management: A comprehensive guide to planning, response, and recovery, eds. E. L. Zdziarski, N. W. Dunkel, \& M. J. Rollo, John Wiley and Sons, Inc.: San Francisco, pp. 285-328, 2007.

[3] Booker Jr., L. (2014). Crisis management: Changing times for colleges. Journal of College Admission, 222, pp. 19-23, 2014.

[4] Hargis, B., Bird, L.E., \& Phillips, B.D., Building resilience to natural disasters across the campus ecosystem. Managing the unthinkable: Crisis preparation and response for campus leaders, eds. G.M. Bataille \& D.I. Cordova, Stylus Publishing LLC: Sterling, pp. 18-36, 2014.

[5] LaBanc, B.H., Krepel, T.L., Johnson, B.J., \& Herrmann, L.V., Managing the whirlwind: Planning for and responding to campus in crisis. Enough is enough: A student affairs perspective on preparedness and response to campus shooting, eds. B.O. Hemphill \& B.H. LaBanc, Stylus Publishing, LLC: Sterling, pp. 53-82, 2010.

[6] Zdziarski II, E.L., Dunkel, N.W., \& Rollo, M.J.(2007). Campus crisis management: A comprehensive guide to planning, response, and recovery, John Wiley \& Sons, Inc.: San Francisco, 2007.

[7] Department of Homeland Security. Critical infrastructure sectors Web Site, available at: www.dhs.gov/critical-infrastructure-sectors. (accessed 24 February, 2017).

[8] The State of Texas. Texas homeland security strategic plan 2015-2020, available at: www.txdps.state.tx.us/director_staff/txHomelandSecStratPlan2015-2020.pdf. (accessed 04 February, 2017).

[9] Brenner, S., Protecting America's colleges and universities. Homeland security: Protecting America's targets, ed. J. Forest, Praeger Security International: Westport, pp. 133-162, 2006.

[10] Department of Homeland Security. Quadrennial Homeland Security Review, available at: www.dhs.gov/sites/default/files/publications/2014-qhsr-final-508.pdf. (accessed 08 February, 2017). 
[11] Department of Homeland Security. Quadrennial Homeland Security Review, available at: www.dhs.gov/sites/default/files/publications/2014-qhsr-final-508.pdf. (accessed 02 Febraury, 2017).

[12] Haddow, G.D., Bullock, J.A., \& Coppola, D.P., Introduction to emergency management, Elsevier: Waltham, 2014.

[13] Kapucu, N., \& Khosa, S., Disaster resiliency and culture of preparedness for university and college campuses. Administration \& Society, 47, pp. 3-37, 2013.

https://doi.org/10.1177/0095399712471626.

[14] Federal Emergency Management Agency, Building a disaster-resistant university, available at: www.fema.gov/media-library-data/20130726-1457-20490-1338/dru_report.pdf. (accessed 26 January, 2017).

[15] A study of active shooter incidents, 2000-2013. Texas State University and Federal Bureau of Investigation, U.S. Department of Justice, Washington D.C. available at: https://www.fbi.gov/about-us/office-of-partner-engagement/active-shooter-incidents/ a-study-of-active-shooter-incidents-in-the-u.s.-2000-2013. (accessed 6 January, 2017).

[16] LSU in the eye of the storm: A university model for disaster response, available at: www.lasfaa.org/docs/news/disaster/SWASFAAPresentation.ppt. (accessed 12 January, 2017).

[17] A President's guide to the Clery Act. American Council on Education, available at: http://www.acenet.edu/news-room/Documents/A-Presidents-Guide-to-the-Clery-Act. pdf. (accessed 08 December, 2016).

[18] Hayter, J.K., Shelley, G.L., \& Stevenson, P., Right-to-Carry and campus crime: evidence from the not-so-wild-west. Libertarian Papers, 6(1), pp. 1-20, 2014.

[19] Gansler, J.S., \& Gast, A.P., Academics and national-security experts must work together. Chronical of Higher Education, 54(44), 2008.

[20] Soft target hardening: Protecting people from attack, available at: http://www.crenetbase.com.ezproxy.shsu.edu/isbn/9781482244229. (accessed 14 November, 2016).

[21] Virginia Tech Review Panel. Mass shootings at Virginia Tech: Report of the review panel, available at: http://www.washingtonpost.com/wp-srv/metro/documents/ vatechreport.pdf. (accessed 28 Decemeber, 2016).

[22] Kerr, Jr., S.D., Disclosure of campus security policies and crime statistics among colleges and universities in the Upper Midwest. Unpublished doctoral dissertation. Vermillion, SD: University of South Dakota.

[23] Nicoll, S.R., \& Owens, R.W., Emergency response and business continuity: the next generation in planning. Professional Safety, 58(9), pp. 50-55, 2013.

[24] Centre for Community Enterprise. The community resilience manual: A resource for rural recovery and renewal, available at: http://www.ontario-sea.org/Storage/37/2905_ Section_1_-_The_Community_Resilience_Manual.pdf. (accessed 02 December, 2016).

[25] Federal Emergency Management Agency. Guide for developing high-quality emergency operations plans for institutions of higher education, available at: https://www.whitehouse. gov/sites/default/files/docs/rems_ihe_guide_508.pdf. (accessed 18 November, 2016).

[26] Perry, R.W., \& Lindell, M.K., Preparedness for emergency response: Guidelines for emergency planning process. Disasters, 27(4), pp. 336-350, 2003. https://doi.org/10.1111/j.0361-3666.2003.00237.x

[27] Homeland Security Presidential Directive 5, available at: https://www.dhs.gov/publication/ homeland-security-presidential-directive-5. (accessed 04 October, 2016). 
[28] Local disaster resilience: Administrative and political perspectives, available at: http://reader.eblib.com.ezproxy.shsu.edu/(S(3pp1c5hvgo5u1ws1tnd3xbhy))/Reader. aspx $? \mathrm{p}=1562246 \& \mathrm{o}=3159 \& \mathrm{u}=\mathrm{KMN} 27 \mathrm{TIaEyc} \% 3 \mathrm{~d} \& \mathrm{t}=1459728400 \& \mathrm{~h}=302254 \mathrm{CCE} 1$ C6BE5387C50DD3661 A263250C9F7CE\&s=43662860\&ut=10382\&pg=1\&r=img\&c $=-1 \&$ pat $=$ n\&cms=-1\&sd=2\#. (accessed 23 February, 2017).

[29] Griffin, O.R., Constructing a legal and managerial paradigm applicable to the modernday safety and security challenge at colleges and universities. St. Louis University Law Journal, 54, pp. 241-270, 2009.

[30] Twigg, J., Characteristics of a disaster-resilient community, 2009. Available at: http:// community.eldis.org/.59e907ee/Characteristics2EDITION.pdf

[31] Federal Emergency Management Agency. Building a disaster-resistant university, available at: http://www.fema.gov/media-library-data/20130726-1457-20490-1338/ dru_report.pdf. (accessed 02 December, 2016).

[32] Creswell, J.W., Research design: Qualitative, quantitative, and mixed method approaches (4th ed.), Sage: Thousand Oaks, 2014.

[33] Yin, R.K., Case study research: Designs and methods (5th ed.), Sage: Thousand Oaks, 2014.

[34] Texas Department of Public Safety, Texas Division of Emergency Management. Texas Emergency Management Executive Guide, pp. 1-108, 2016.

[35] Texas Department of Public Safety, Texas Division of Emergency Management. State of Texas Hazard Mitigation Plan 2010-2013, pp. 1-366, 2010.

[36] Beggan, D.M., The impact of Hurricane Rita on an academic institution: Lessons learned. Disasters, 34(1), pp. 93-111, 2010. https://doi.org/10.1111/j.1467-7717.2009.01116.x

[37] Disaster Declarations for Texas, available at: https://www.fema.gov/disasters/grid/ state-tribal-government/24. (accessed 02 December, 2016).

[38] Patrol response to contemporary problems: enhancing performance of first responders through knowledge and experience. Charles C. Thomas: Springfield, 2006.

[39] Walton, W.D., Bryner, N.P. \& Jason, N.H., Fire Research Needs Workshop. Proceedings: Presented at Maryland, October 20, 1999.

[40] U.S Chemical Safety Board. CSB Releases Investigation into 2010 Texas Tech Laboratory Accident, available at: http://www.csb.gov/csb-releases-investigation-into-2010-texastech-laboratory-accident-case-study-identifies-systemic-deficiencies-in-universitysafety-management-practices/. (accessed October 16, 2016).

[41] University of Texas System Board of Regents policy. UT 172 Emergency Management, Board of Regents Policy, available at: https://www.utsystem.edu/board-of-regents/ policy-library/policies/uts172-emergency-management. (accessed 04 January, 2017).

[42] Southern Association of Colleges and Schools Commission on Colleges, available at: http://www.sacscoc.org/about.asp. (accessed 08 September, 2016).

[43] Southern Association of Colleges and Schools Commission on Colleges. Resource Manual for the Principles of Accreditation (pp. 1-151), 2012.

[44] What are Title IV Programs?, available at: http://federalstudentaid.ed.gov/site/front2back/programs/programs/fb_03_01_0030.htm. (accessed 12 February, 2017).

[45] Berelson, B., Content analysis in communicative research. Free Press: New York, 1952.

[46] Wilcox, F.D., The American newspaper: A study in social psychology. Annals of the American Academy of Political and Social Science, 16, pp. 56-92, 1990. 
[47] Onwuegbuzie, A.J., \& Denham, M.A., Qualitative data analysis techniques. Oxford Bibliographies in "Educationß. Oxford University Press: New York, 2014.

[48] Leech, N.L., \& Onwuegbuzie, A.J., An array of qualitative data analysis tools: a call for qualitative data analysis triangulation. School Psychology Quarterly, 22, pp. 557-584, 2007. https://doi.org/10.1037/1045-3830.22.4.557

[49] Miles, M.B., Huberman, A.M., \& Saldaña, J., Qualitative data analysis: a methods sourcebook (3rd ed.). Sage: Thousand Oaks, 2014.

[50] Michailidis, G. Correspondence analysis. Encyclopedia of measurement and statistics, ed. N. J. Salkind, Sage: Thousand Oaks, pp. 191-194, 2007.

[51] Provalis Research. QDA Miner (Version 5.0.5) [Computer software]. Montreal, Quebec, 2016.

[52] Onwuegbuzie, A.J., \& Combs, J.P., Emergent data analysis techniques in mixed methods research: A synthesis. In: Sage handbook of mixed methods in social and behavioral research (2nd ed.), eds. A. Tashakkori \& C. Teddlie, Sage: Thousand Oaks, pp. 397-430, 2010.

[53] Sahebjamnia, N., Torabi, S.A., \& Mansouri, A., Integrated business continuity and disaster recovery planning: towards organizational resilience. European Journal of Operational Research, 242, pp. 261-273, 2015. https://doi.org/10.1016/j.ejor.2014.09.055

[54] Somers, S., Measuring resilience potential: an adaptive strategy for organizational crisis planning. Journal of Contingencies and Crisis Management, 17(1), pp. 12-23, 2009. https://doi.org/10.1111/j.1468-5973.2009.00558.x

[55] Local disaster resilience: Administrative and political perspectives, available at: http://reader.eblib.com.ezproxy.shsu.edu/(S(3pp1c5hvgo5u1ws1tnd3xbhy))/Reader. aspx $? \mathrm{p}=1562246 \& \mathrm{o}=3159 \& \mathrm{u}=\mathrm{KMN} 27 \mathrm{TIaEyc} \% 3 \mathrm{~d} \& \mathrm{t}=1459728400 \& \mathrm{~h}=302254 \mathrm{CCE} 1$ C6BE5387C50DD3661A263250C9F7CE\&s=43662860\&ut=10382\&pg=1\&r=img\&c =-1\&pat=n\&cms=-1\&sd=2\#. (accessed 23 February 2017). 